\section{No effect of RDGS peptides}

SIR - Peptides containing the sequence Arg-Gly-Asp-Ser (RDGS), which, in vertebrates, inhibit the binding of fibronectin and other ligands to their receptors ${ }^{1}$, have been reported by Naidet et al. ${ }^{2}$ to interfere with gastrulation or the establishment of the dorsoventral axis in Drosophila. But the known Drosophila integrins are not required for gastrulation or dorsoventral axis formation ${ }^{3}$. In view of the facts that one of the genes responsible for organizing the dorsoventral axis in the Drosophila embryo encodes a serine protease with the sequence RGDS in its active $\operatorname{site}^{4}$, and that dorsoventral axis formation can be inhibited by the injection of protease inhibitors ${ }^{5}$, we attempted to repeat the experiments in which RGDS-peptides are injected into Drosophila embryos to test whether they act in the same way as protease inhibitors.

We found that the peptide GRGDSP had no effect on Drosophila gastrulation or dorsoventral axis formation, even when we used peptide solutions with concentrations up to $100 \mathrm{mg} \mathrm{ml}^{-1}$. These solutions were simultaneously tested and shown to be active (at $1 \mathrm{mg} \mathrm{m}^{-1}$ ) in a Xenopus cell culture system where they inhibited the adhesion and spreading of mesodermal cells on fibronectin. The peptide was injected at different times and into different parts of the embryo, testing in each case at least 200 embryos. Most injected embryos developed normally through gastrulation.

We tested various aspects of these embryos' development. They formed a normal ventral furrow and extended their germ band normally during gastrulation. Neither of these processes occurs in genetically or experimentally dorsalized embryos. We fixed injected embryos at early gastrulation stages and stained them with antibodies against the twist protein as an assay for changes of the dorsoventral fate map. These embryos were indistinguishable from wild-type embryos. Finally, we prepared cuticles from injected embryos that had been left to complete embryogenesis. We found no signs of defective gastrulation or of dorsalization in these cuticles. Neither when protease inhibitors are effective (nuclear division cycle 6-10), nor at the time RGDS peptides were reported to be active (cycle 12-13) did the peptide affect development. It also made no difference whether the peptide

1. Hynes, R. Cell 48, 549-554 (1987)

2. Naidet, C., Semeriva, M., Yamada, K. M. \& Thiery, J. P. Nature 325, 348-350 (1987)

3. Leptin, M., Bogaert, T., Lehmann, R. \& Wilcox, M. Cell 56, 401-8 (1989)

4. Chasen, R. \& Anderson, K. V. Cell 56, 391-400 (1989).

5. Stein, D. \& Nüsslein-Volhard, C. Cell 68, 429-440 (1992).

NATURE · VOL $355 \cdot 27$ FEBRUARY 1992 was injected into the periplasm (the cytoplasm near the egg surface) or the perivitelline space (the liquid-filled space surrounding the egg, in which the protease is thought to act, and in which ligands for cell surface receptors would be expected to be found).

Thus the dorsoventral system and gastrulation are not inhibitable by RGDS. Indeed, as we were unable to observe any effects of RGDS peptides (with the exception of minor distortions at the anterior and posterior poles of the embryo), the effects observed by Naidet et al. might have to be ascribed to something other than RGDS peptides.

MARIA LEPTIN

BARBARA GRUNEWALD DAVID STEIN

\author{
Max-Planck-Institut für \\ Entwicklungsbiologie, \\ Spemannstr. 35 , \\ 7400 Tübingen, Germany
}

\title{
Protein engineering in haemoglobin
}

SIR - The paper by Komiyama et al. ${ }^{1}$ on the structural and functional significance of the D helix in human adult haemoglobin (HbA) has important evolutionary implications, particularly concerning assembly of proteins into tetrameric structures.

In $\mathrm{HbA}, \mathrm{O}_{2}$ binding at the haems is modulated by functional interactions with heterotropic ligands such as protons, inorganic and organic ions. Temperature also has a large effect on the $\mathrm{O}_{2}$ affinity of $\mathrm{HbA}$ so that heat absorption and release can be considered a physiologically relevant modulating factor, similar to heterotropic ligands. Many interesting adaptation mechanisms involving the interplay of temperature with heterotropic ligands may be missed when experiments are performed under only one set of conditions and a single temperature.

Human fetal haemoglobin $(\mathrm{HbF})$ displays at $20^{\circ} \mathrm{C}$ a lower affinity for $\mathrm{O}_{2}$ than $\mathrm{HbA}$ in the absence of organic phosphates ${ }^{2}$. The physiologically important reverse situation is achieved at $37^{\circ} \mathrm{C}$ upon addition of 2,3-diphosphoglycerate (DPG), whose effect on $\mathrm{HbF}$ is related to some amino-acid substitutions present in $\gamma$ chains ${ }^{3}$. However, the difference in $\mathrm{O}_{2}$ affinity observed at $37^{\circ} \mathrm{C}$ is not solely due to the different modulation power of DPG with respect to $\mathrm{HbA}$ and $\mathrm{HbF}$. In fact, when different experimental conditions are taken into account, new aspects linked to the interplay of temperature and organic phosphates are revealed. The effect of DPG on $\mathrm{HbF}$ renders almost identical the $\mathrm{O}_{2}$ affinity of the haemoglobins at $20^{\circ} \mathrm{C}$, abolishing the difference observed in the absence of the effector. On going from 20 to $37^{\circ} \mathrm{C}$, by virtue of the lower overall heat of oxygenation $(\Delta H)$ displayed by $\mathrm{HbF}$ when in the presence of DGP $\left(\Delta H=-5.5 \mathrm{kcal} \mathrm{mol}^{-1}\right.$ of $\mathrm{O}_{2}$ for $\mathrm{HbF}$ and $-8.7 \mathrm{kcal}^{-1} \mathrm{mbA}$ at $\mathrm{pH} 7.4$ and corrected for the heat contribution of $\mathrm{O}_{2}$ in solution), $\mathrm{HbA}$ shows a lower $\mathrm{O}_{2}$ affinity, as should be the case if $\mathrm{O}_{2}$ has to be transferred from maternal to fetal blood.

We would like to comment on the experimental data reported by Komiyama et al. in the light of this striking example. These authors make the important contribution that the presence or the absence of $\mathrm{D}$ helix does not affect assembly at $\alpha$ and $\beta$ chains into cooperative tetramers, implying that this assembly and the loss of the D helix in $\alpha$ subunits could have been independent events in haemoglobin evolution. But as far as the functional properties are concerned, the experiments reported by Komiyama et al. show only that the haemoglobin molecule does not need the $D$ helix on the $\beta$ subunits under the conditions used (which unfortunately are not indicated). Hence we still do not know if the absence of the $\mathrm{D}$ helix induces some important alterations. At this stage it is too early to say that "the role of the D helix may simply be to link the C and E helices" or that "it is remarkable that the loss or addition of the D helix has such a small effect on $\mathrm{O}_{2}$ binding properties and stability". A detailed functional characterization taking into account the whole network of functional interactions is needed.

B. Giardina, R. SCATENA

M. E. Clementi, L. Cerroni, S. G. CONDO

Department of Experimental Medicine and Biochemical Sciences,

University of Rome "Tor Vergata", 00173 Rome, Italy

M. NUUTINEN

Department of Pediatrics,

University of Oulu, Oulu, Finland

O. BRIX

Zoological Laboratory,

University of Bergen, Bergen, Norway

NAGAI ET AL. REPLY - Giardina et al. discuss an interesting instance of the effect of temperature on the oxygen affinity of two haemoglobins, $\mathrm{HbA}$ and $\mathrm{HbF}$. Because $\mathrm{HbF}$ has a lower oxygen affinity than $\mathrm{HbA}$ at $20^{\circ} \mathrm{C}$, but a higher oxygen affinity at $37^{\circ} \mathrm{C}$ in the presence of 2, 3 diphosphoglycerate, Giardina et al. suggest that our conclusions' ${ }^{\prime}$ regarding the functional role of the $\mathrm{D}$ helix from experiments carried out at only one temperature were premature. We would 